\title{
Therapeutic effect of low molecular weight chitosan containing sepia ink on ethanol- induced gastric ulcer in rats ${ }^{1}$
}

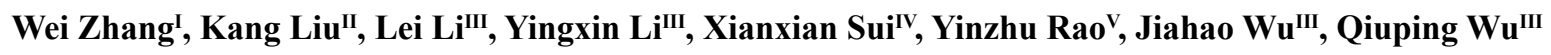 \\ DOI: http://dx.doi.org/10.1590/S0102-865020160120000006
}

IFellow Master degree, Postgraduate Program in Biomedcial Materimals, Lingnan Normal University, Round Beibu Gulf Institute for the Protection and Utilization of Marine Animals in Medicine (RBGPUM), China. Conception, design, intellectual and scientific content of the study; acquisition and interpretation of data; manuscript writing.

" $\mathrm{PhD}$, The Key Laboratory of nutrition and feed, College of Fisheries, Guangdong Ocean University, China. Design of the study, technical procedures. IIIUndergraduates, Life Science and Technology School, Lingnan Normal University, China. Acquisition of data.

${ }^{\mathrm{IV}} \mathrm{PhD}$, Department of Pathology and Pathological Physiology, Shanghai Medical College, Fudan University, China. Design of the study, acquisition and interpretation of data, technical procedures.

vAssociate Professor, Postgraduate Program in Medicinal Animals, Lingnan Normal University, RBGPUM, China. Conception, design, intellectual and scientific content of the study.

\section{ABSTRACT}

PURPOSE: To evaluate the role of low molecular chitosan containing sepia ink (LMCS) in ethanol-induced (5 ml/kg) gastric ulcer in rats.

METHODS: Animals were divided into four groups $(\mathrm{n}=12)$ : normal group (Normal), negative control group (Con), experiment group (LMCS) and positive control Omeprazole group (OMZ). Gastric empty rate was detected in the first 7 days. Rats were sacrificed at 7 , 14 and 21 day for histology and ELISA detections.

RESULTS: Gastric empty was no significant differences among the groups $(P>0.05)$. Histological observation showed gastric mucosal LMCS treated had better healing effect. Hydroxyproline (Hyp) was significantly increased from 7 day $(P<0.05)$. LMCS significantly inhibited malondialdehyde (MDA) generation for lipid peroxidation from 7 day $(P<0.05)$. LMCS significantly promoted the activity of superoxide dismutase (SOD), catalase (CAT) and glutathione peroxidase (GPx) at the earlier stage $(P<0.05)$. OMZ had the similar effects above. As for myeloperoxidase (MPO), LMCS significantly decreased and restored it to normal levels from 7 day $(P<0.05)$, it is earlier than $\mathrm{OMZ}$ which is from 14 day.

CONCLUSION: LMCS can improve gastric mucosa tissue repair, exert significant influences on oxidative and antioxidant enzyme activities and neutrophil infiltration.

Key words: Chitosan. Sepia. Stomach Ulcer. Hydroxyproline. Malondialdehyde. Rats. 


\section{Introduction}

Gastric ulcer is a common gastrointestinal disease with multiple etiologies and it is prevalent worldwide ${ }^{1}$. The pathogenesis of gastric ulcers includes stress, smoking, alcohol consumption, infections caused by Helicobacter pylori, and frequent and indiscriminate use of non-steroidalanti-inflammatory drugs (NSAIDs) ${ }^{2}$.

The gastric mucosa is important tissue because of its structure and function, which can reflect the pathological processes by the inflammation changes of gastric ulcer ${ }^{3}$. The mucosal defense has been best characterized in the gastric, which exhibits remarkable resistance to the damaging effects of acid and pepsin ${ }^{4}$.

Currently, many different anti-ulcer drugs including proton pump inhibitors and $\mathrm{H}_{2}$ receptor antagonists are available for the treatment of peptic ulcer disease, however, clinical evaluation has shown various side effects and incidence of relapse of these drugs $^{5}$. The ever-increasing problem of gastric ulcer necessitated the development and screening novel gastroprotective agents from natural polymers, which might be less toxic and cost-effective ${ }^{6}$.

Natural polymers are widely used in medical fields ${ }^{7}$. Especially, chitosan is biodegradable, biocompatibile and bioadhesive, and it increases the solubility of hydrophobic drugs ${ }^{8}$. It's biological application depends on its molecular weight and its deacetylation degree ${ }^{9}$. Chitosan with high molecular weight displays high viscosity and low water solubility, which limits its use $^{10}$. Low molecular weight chitosan (LMC) has overcome these limits, and it is more readily to be absorbed by organism. Moreover, it has been proved that LMC possesses many outstanding health benefits such as anti-inflammatory, immunity regulation, antibacterial, antioxidant, and antilipid peroxidation ${ }^{11}$.

Also, sepia ink is a traditional medicine used in the treatment of hemostasis for centuries in China ${ }^{12}$, and some researchers have founded that sepia ink has anti-radiation activity, antioxidant activity, antitumor activity, immunomodulatory activity, procoagulant function, etc $^{13}$. It can improve the functional status of the whole body ${ }^{14}$.

In this experiment, a novel biocompatible material, low molecular weight chitosan containing sepia ink (LMCS) was prepared for treating ethanol-induced gastric ulcer, which mainly based on two considerations. LMC can form adhesive colloidal solution under acidic conditions in gastric to protect the gastric mucosa from persistent injury, and promote the tissue repair; sepia ink can be used as a hemostatic and antioxidant agent in the ulcer site. The main purpose of this study was to detect whether LMCS has a positive therapeutic effect in gastric ulcer of rats and the potential underlying mechanism.

\section{Methods}

This project was reviewed and approved by the committee of experimental animals of Lingnan Normal University and conformed to National Institutes of Health guidelines.

Wistar rats $(200 \pm 20 \mathrm{~g})$ were purchased from the Medical Experimental Animal Center of Guangdong Province. Animals were provided with standard pellet diet and water ad libitum during the experiment period. Animals were maintained in $12 \mathrm{~h}$ light dark cycle and room temperature of $24 \pm 3^{\circ} \mathrm{C}$.

\section{Surgical procedures and groups formation}

Forty eight rats were deprived of food but had ad libitum access to tap water for $48 \mathrm{~h}$ before ulcer induction. Gastric ulcer model was induced in conscious rats by gavages of absolute ethanol $(5 \mathrm{ml} / \mathrm{kg})^{15}$. The rats were randomized into four groups $(\mathrm{n}=12)$ : Normal group (Normal), negative control group (Con), experiment group (LMCS) and positive control Omeprazole group (OMZ). An hour later, treatment of each group carried out simultaneously. The gavage dosage of LMCS in experiment group is $7.6 \mathrm{mg} / \mathrm{kg}$ which was counted from the mount of human requirement ${ }^{12}$; and $\mathrm{OMZ}$ in positive control group is $5.5 \mathrm{mg} / \mathrm{kg}$ which was calculated from the medication instructions; negative control group was without treatment process, but with a standard dose of saline gavage; normal group did not been treated for gastric ulcer, which was only taken samples for detection at each time point. Finally, all rats were gavage once a day and then free access to food and water.

In parallel, each group of rats was sacrificed on 7, 14 and 21 day. The rat gastric was rapidly removed and opened along the greater curvature and rinsed with normal saline. Thereafter, each gastric was dichotomized, with one moiety of gastric immersed in neutral formalin for histological evaluation and gastric mucosa from the other moiety stored at $-80^{\circ} \mathrm{C}$ for biochemical determinations.

\section{Determination of gastric emptying rate}

As an indication of the restoration of gastric function, gastric emptying rate was detected on the seventh day after ulcer induction.After fasting for $48 \mathrm{~h}$, thenrats were given $30 \mathrm{~g}$ standard pellets and water ad libitum. 3 three hours later, the spilled pellets were removed and food intake was recorded. Water was prohibited for next $5 \mathrm{~h}$, then rats were decapitated and the gastric was removed and weighed. Then opened along the greater curvature and rinsed thoroughly with normal saline, gastric was blotted dry 
and weighed again. Gastric emptying rate was calculated through the formula:

Gastric emptying $(\%)=(1-$ gastric content/food intake $)$ $\times 100$

\section{Pathology assessment}

For histological evaluations, gastric was opened by an incision along the greater curvature, fastens and expanded on a plexiglass. Then gastric tissues were then fixed in $10 \%$ neutral formalin and embedded in paraffin wax. Sections were made and stained by routine Hematoxylin and Eosin (H\&E) staining for histological evaluation and Masson's Trichrome staining for collagen evaluation.

\section{Hydroxyproline content}

Hydroxyproline (Hyp) content was determined through alkaline hydrolysis method by ELISA (Shanghai, China). $50 \mathrm{mg}$ gastric tissue sample and $1.0 \mathrm{ml}$ hydrolyzate were mixed in a test tube, and put into boiling water bath for $20 \mathrm{~min}$. According to the instruction, blank tube, standard tube and measuring tube were respectively added $1.0 \mathrm{ml}$ distilled water, $1.0 \mathrm{ml}$ standard solution and $1.0 \mathrm{ml}$ test sample. Followed by, $0.5 \mathrm{ml}$ regent I was added and standing for $10 \mathrm{~min}$ after mixing; $0.5 \mathrm{ml}$ regent II was added and standing for $5 \mathrm{~min}$ after mixing; $0.5 \mathrm{ml}$ regent III was added and kept in water bath at $60^{\circ} \mathrm{C}$ for $15 \mathrm{~min}$ after mixing.Finally, the tubes were cooled in water and centrifuged at $3500 \mathrm{rpm}$ for $10 \mathrm{~min}$ to obtain supernatants, then absorbance values was measured at $550 \mathrm{~nm}$ and Hyp content was calculated according to the ELISA kit.

\section{Oxidative damage and antioxidant radical scaveng- ing enzymes determination}

Gastric tissues washed with PBS, homogenized on ice for $10 \mathrm{~min}$. Supernatant fraction collected over from $15 \mathrm{~min}$ of centrifugation at $12,000 \mathrm{rpm}$ was accordingly extracted in lysis buffer (10 mM Tris-HCl, pH 8.0, $150 \mathrm{mMv} \mathrm{NaCl,} \mathrm{1 \%} \mathrm{Triton}$ $\mathrm{X}-100$, and protease inhibitors). The extracts were separated by centrifugation at $12.000 \mathrm{rpm}$ for $15 \mathrm{~min}$. The viabilities of different antioxidant enzymes were measured by conducting the homogenization of rat gastric tissue. Malondialdehyde (MDA), Superoxide dismutase (SOD) and Catalase (CAT) activity were detected using the commercial assay kits (Shanghai, China). Glutathione peroxidase (GPx) activity in tissue homogenate was determined according to literature ${ }^{16}$.

\section{Myeloperoxidase assay}

Myeloperoxidase (MPO) is used as a quantitative index of inflammation. $0.3 \mathrm{~g}$ gastric tissue samples were homogenized in 10 volumes of ice-cold potassium phosphate buffer $(20 \mathrm{mM}$ $\mathrm{K}_{2} \mathrm{HPO}_{4}, \mathrm{pH}$ 7.4). The homogenate was centrifuged at 10,000 rpm for $20 \mathrm{~min}$ at $4^{\circ} \mathrm{C}$. Then pellet was homogenized with an equivalent volume of $50 \mathrm{mM}$ acetic acid (pH 6.0) containing $0.5 \%$ (w/v) hexadecyltrimethyammonium bromide (HETAB). MPO activity was assessed by measuring $\mathrm{H}_{2} \mathrm{O}_{2}$-dependent oxidation of 3,3',5,5-tetramethylbenzidine. One unit of MPO activity was defined as the MPO present that caused a change inabsorbance of $1.0 \mathrm{~min}$ at $655 \mathrm{~nm}$ and $37^{\circ} \mathrm{C}$.

\section{Statistical analysis}

All results were expressed as means \pm standard deviation (S.D.) and SPSS 17.0 software was used to analyze the data of the test. The means of the different groups were using one-way Kruskal-Wallis test. Values of $\mathrm{P}<0.05$ were regarded as significant.

\section{Results}

\section{Properties of low molecular weight chitosan con-} taining sepia ink

The dry low molecular weight chitosan containing sepia ink (LMCS) used in this experiment is black powder substance. The viscosity of $3 \%$ LMCS under the same acidic condition in gastric of rats ( $\mathrm{pH} 3.2)$ is $25.2 \mathrm{mPa}$.s (Figure 1). It exhibits good adhesion, which would protect the inner surface ulcers of the gastric.

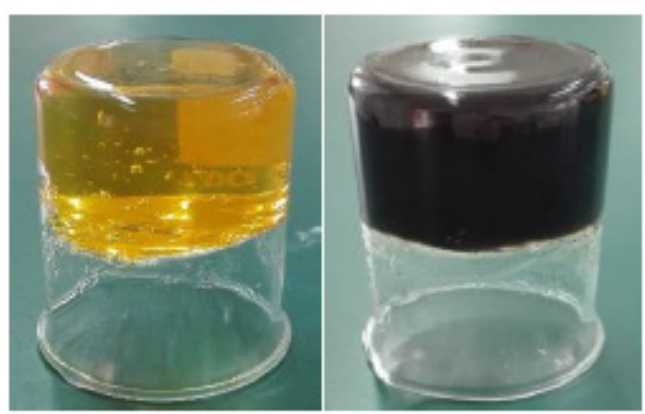

A

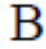

FIGURE 1 - A. Cross-linked low molecular weight chitosan. B. Crosslinked low molecular weight chitosan containing purified sepia ink. 


\section{Gastric emptying rate assessment}

From the experimental results, gastric emptying rate in Normal group, Control group and OMZ group was respectively $81.0 \pm 2.9 \%, 72.4 \pm 4.3 \%$ and $80.5 \pm 3.5 \%$. Comparing to LMCS group $79.8 \pm 3.8 \%$, there was no significant difference $(\mathrm{P}>0.05)$, although an increasing tendencywas obvious.

\section{Pathology evaluation of gastric ulcers}

Histological observation showed absolute ethanol caused severe lesion and extensive damage to the gastric mucosa (Figure 2b). On 7 day in Con group, the symptom of edema, severe hemorrhage, leukocytes infiltration and destruction of the mucosa surface were relatively obvious (Figure 2A7). Until 21 day in Con group, the gastric mucosa epithelium still had obvious edema and partial defect, and accompanied by mild mucosal hemorrhage (Figure 2A21). In LMCS group on 7day, it was seen that edema symptom was mild and gastric mucosa was relatively intact, mucosal columnar epithelial cell arranged neatly (Figure 2B7). When came to 21 day in LMCS group, the gastric mucosa was nearly no major differences compared with normal group (Figure 2B21, a). OMZ group and LMCS group had similar healing effect, but the differences also existed. LMCS had a certain inflammatory response in early time (Figure 2B7), which nearly disappeared from 14 to 21day (Figure 2B14, B21). As for OMZ group, the inflammatory response was observed obviously from 14 to 21 day (Figure 2C14, C21), but the early time was slight (Figure 2C7).

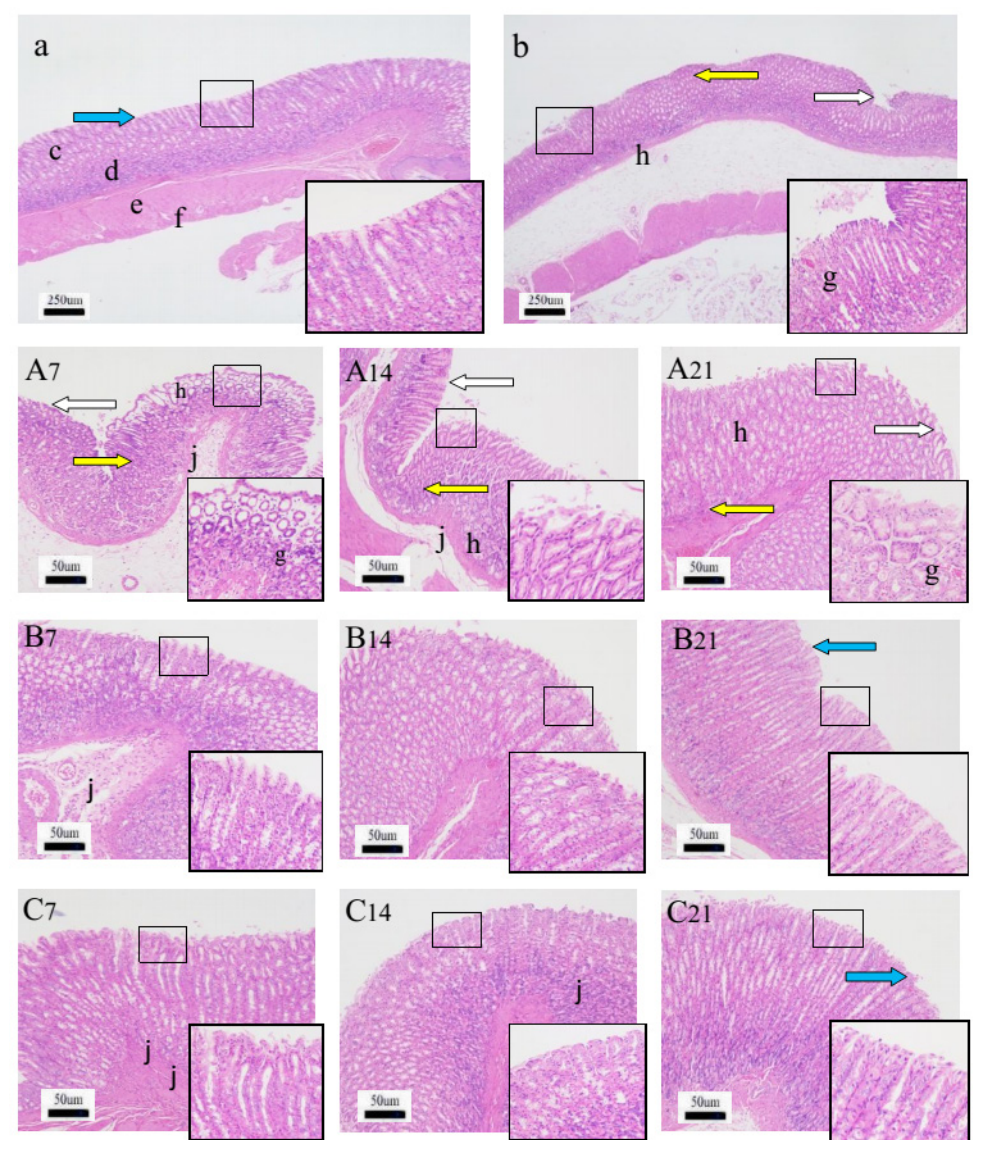

FIGURE 2 - Histological detection of gastric mucosa in the ethanol-induced ulcerated rats (H\&E staining). (a) Gastric mucosa of normal rats, (b) Gastric ulcers model of ethanol-induced rats, (A7-A21) Gastric mucosa of negative control group on 7, 14 and 21day, (B7-B21) Gastric mucosa of LMCS group on 7, 14, 21 day, (C7-C21) Gastric mucosa of OMZ group on 7, 14 and 21 day. Yellow arrow indicates severe hemorrhageand disruption to the deep mucosa layer. White arrow indicates disruption to the surface epithelium. Blue arrow shows intact appearance of histological structureof the epithelium and mucosa layer; e-mucosa; d-submucosa; e-muscularis; f-serosa; h-edema; j-leukocyte infiltration;g-hemorrhage.

Collagen can be dyed blue through Masson staining, by which we can roughly evaluate the healing effect at the macro level. Figure 3 indicated the synthesis of new collagen at different time points. On 7 day, both LMCS and OMZ groups obviously contained more collagen than Con group (Figure 3D7, E7, F7), and the similar results also appeared on the 14 day (Figure D14, E14, F14). By the 21 day, there was an obvious increase of the content of collagen in Con group than earlier time (Figure 3D21). Meanwhile, the content of collagen in LMCS and OMZ groups decreased (Figure E21, F21). 


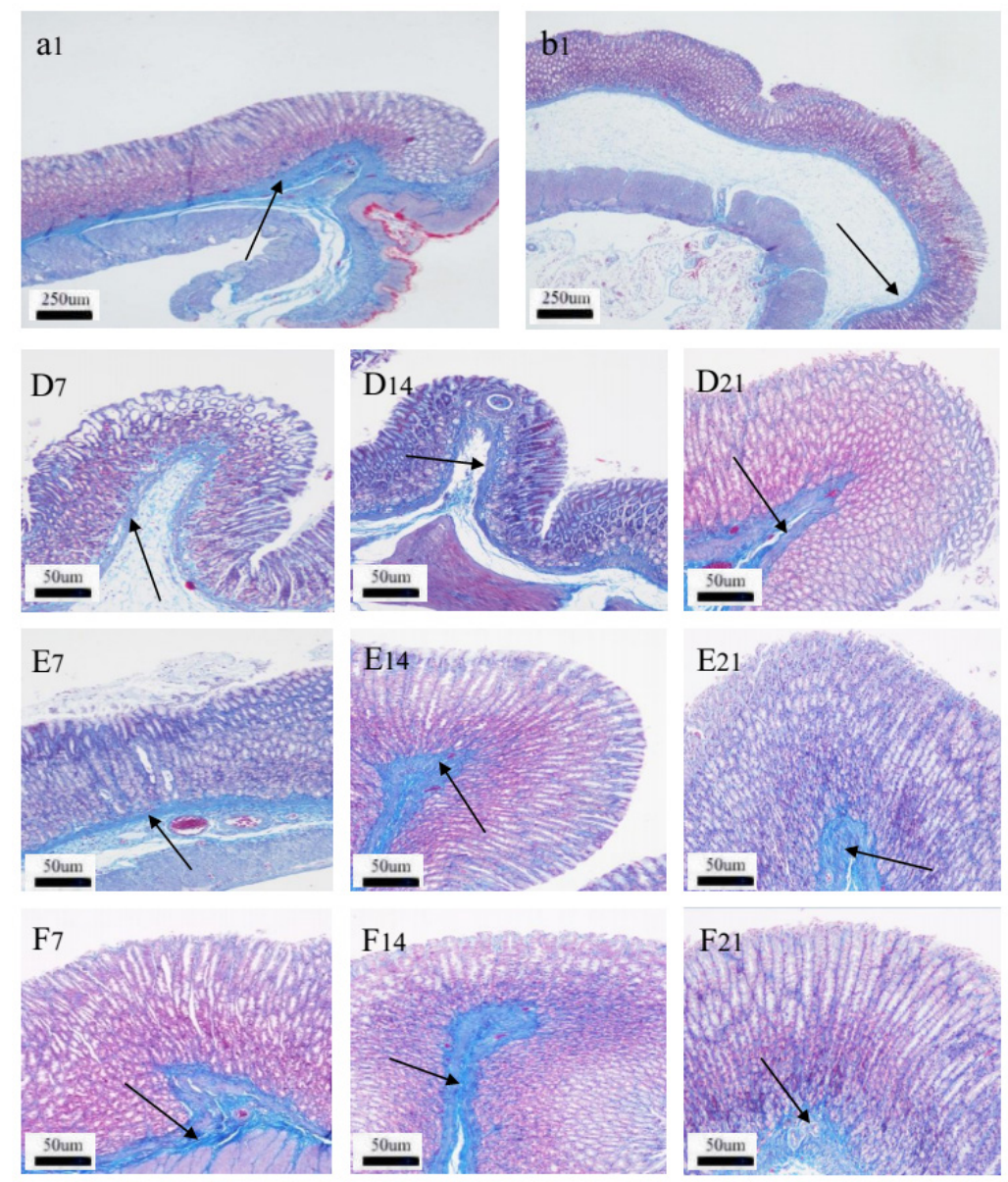

FIGURE 3 - Histological evaluation of gastric mucosa in the ethanol-induced ulcerated rats (Masson staining). (a) Gastric mucosa of normal rats, (b) Gastric mucosa of absolute ethanol-induced rats, (D7-D21) Gastric mucosa of negative control group on 7, 14 and 21 day, (E7-E21) Gastric mucosa of LMCS group on 7, 14, 21 day, (F7-F21) Gastric mucosa of OMZ group on 7, 14 and 21 day. The black arrow is the new collagen fiber in the healing process of gastric mucosa, which was dyed blue.

\section{Content of hydroxyproline assays}

As shown in Figure 4, Hyp content in LMCS group was significantly stimulated comparing to Con group from 7 to 14 day $(\mathrm{P}<0.05)$. There was a similar variation trend in OMZ group. But both LMCS and OMZ group dropped to normal level on 21 day.

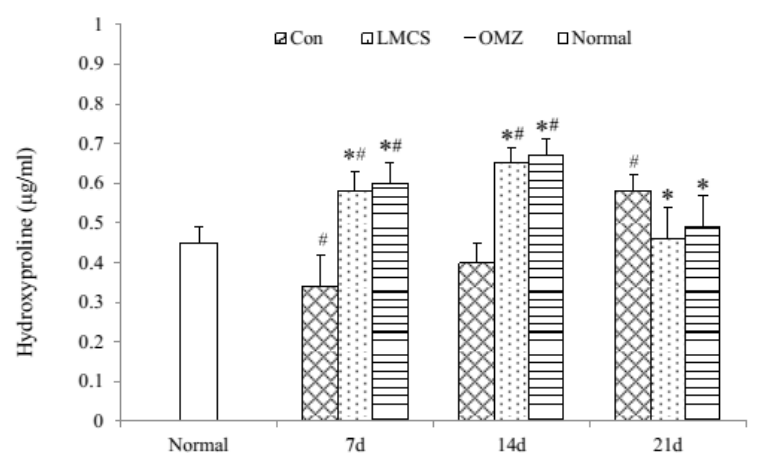

FIGURE 4 - Effects of LMCS, OMA on the Hyp content in stomach tissue of ethanol-induced gastric ulcer in rats. Results are expressed as mean $\pm \mathrm{SD}(\mathrm{n}=3) .\left({ }^{*} \mathrm{p}<0.05 v\right.$ s. Con group and $\# \mathrm{p}<0.05$ vs. Normal group).

\section{Oxidative damage and antioxidant enzymes deter-} mination

Figure 5 indicated that ethanol caused a significant increase of MDA from 7 to 21 day in Con group $(\mathrm{P}<0.05)$. Compared to Con group, there was an significant inhibitory effect in LMCS and OMZ group on the content of MDA $(\mathrm{P}<0.05)$, which also earlier decreased to normal level on 21 day.

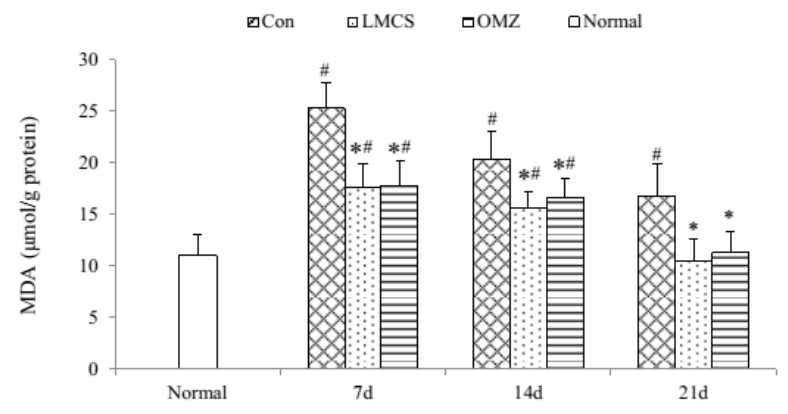

FIGURE 5 - Effects of LMCS, OMZ on the MDA content in stomach tissue of ethanol-induced gastric ulcer in rats. Results are expressed as mean $\pm \mathrm{SD}(\mathrm{n}=3) .\left({ }^{*} \mathrm{p}<0.05 v\right.$ s. Con group and $\# \mathrm{p}<0.05 v$ s. Normal group). 
The results of Figure 6 suggested that LMCS and OMZ played a similar regulatory role on the activities of CAT, SOD and GPx enzymes, which were all significantly enhanced at earlier time on 7 day $(\mathrm{P}<0.05)$, and came to normal level on 14 day, except GPx on 21 day.

$\mathbf{A}$

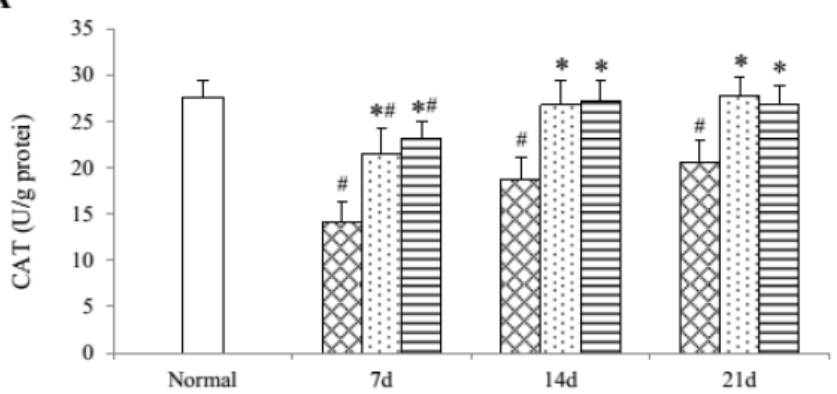

B
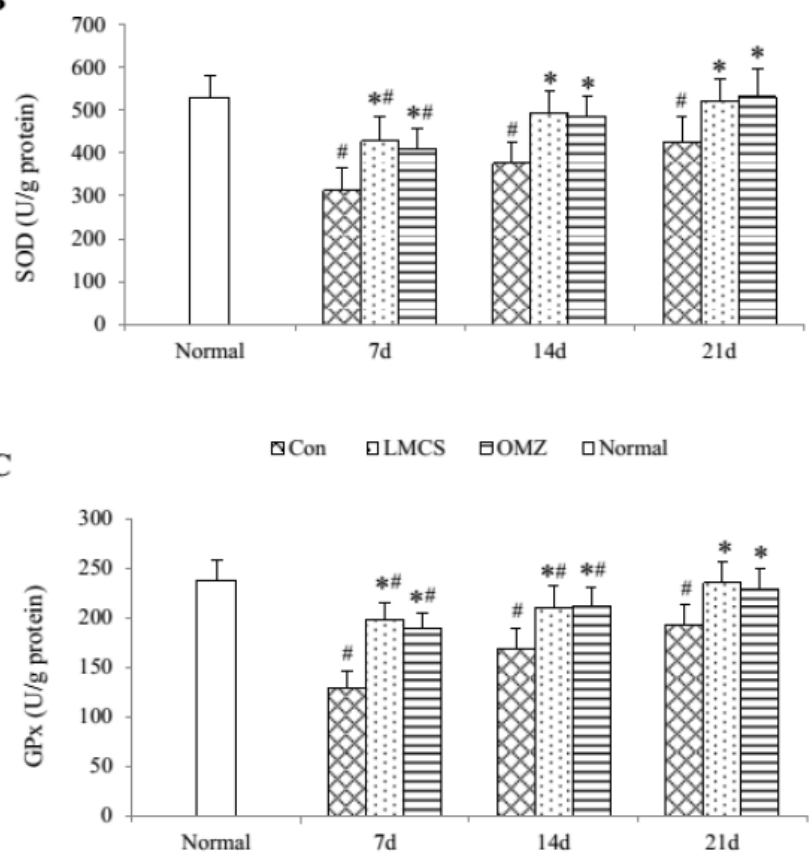

FIGURE 6 - Effects of LMCS, OMA on activities of free radical scavenging enzyme in the gastric tissue of ethanol-induced gastric ulcer in rats. (A) Catalase activity. (B) Superoxide dismutase activity. (C) Glutathione peroxidase activity. Results are expressed as mean \pm SD $(\mathrm{n}=3) .\left({ }^{*} \mathrm{p}<0.05 v s\right.$. Con group and $\# \mathrm{p}<0.05 v s$. Normal group).

\section{Myeloperoxidase assay}

Figure 7 depicted that the activity of MPO comparing to normal group were all significantly inhibited on 7 day $(\mathrm{P}<0.05)$, and this inhibition degree in LMCS group was more significant comparing to Con group $(\mathrm{P}<0.05)$. When came to the 21 day, the content of MPO in Con group was still significantly higher than Normal group $(\mathrm{P}<0.05)$.

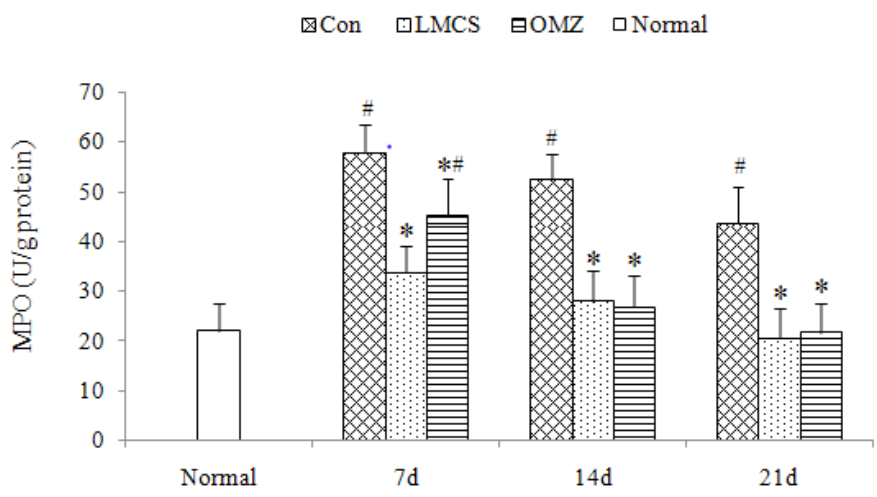

FIGURE 7 - Effects of LMCS, OMZ on the MPO content in stomach tissue of ethanol-induced gastric ulcer in rats. Results are expressed as mean $\pm \mathrm{SD}(\mathrm{n}=3) .\left({ }^{*} \mathrm{p}<0.05\right.$ vs. Con group and $\# \mathrm{p}<0.05$ vs. Normal group).

\section{Discussion}

Ethanol-induced gastric ulceration is a classic model that is widely used to investigate the gastroprotective activity of drugs ${ }^{17}$. The mechanisms of ethanol-induced gastric ulcer mainly includes breaking the mucosal barrier, back diffusion of acid, increased gastric mucosal permeability and depletion of certain oxygen free radical scavengers ${ }^{18}$. Also, metabolism of ethanol also releases free radicals ${ }^{19}$. In the present study, we evaluated the therapeutic effect of LMCS on ethanol-induced gastric ulcer in rats, and results manifested that oral administration of LMCS $(7.6 \mathrm{mg} / \mathrm{kg})$ has obviously promoting healing effect. Our previous work had illuminated that chitosan and sepia ink has good biocompatibility and regulation effect for gastrointestinal diseases ${ }^{12}$. But the underlying therapeutic mechanism of compound LMCS in gastric ulcer is still unclear. Hence, we carried out a preliminary analysis in this experiment.

Results showed that gastric emptying rate in LMCStreated group at the first week reached to normal levels, which meant that LMCS had good effect on the regulation of gastric functions. Microscopical assessment revealed that at tissue level, LMCS had a healing promoting effect and the healing level of gastric ulcer was close to normal tissue on 21 day (Figure 2B21). Also, it exhibited less edema and bleeding point in the early stage (Figure 2B7, B14). Collagen expression is often used to evaluate the healing rate of wounds. Collagen is mainly secreted by fibroblasts, which is critical for ulcer healing ${ }^{20}$. Hydroxyproline (Hyp), as a characteristic amino acid of collagen, are often used as an indicator for detecting the collagen content ${ }^{21}$. Present study in Figure 3 showed that the fibroblasts in mucosa lamina of LMCS group secreted more collagen fibers compared to Con group at the testing time. Collagen fibers contained in OMZ 
group exhibited also increased (Figure 3F7), but it is more orderly distribution in LMCS group (Figure 3E7). What's more, through the determination of Hyp showed that LMCS and OMZ indeed promoted collagen fiber growth in the ulcer (Figure 4).

Experimental studies had indicated that reactive oxygen species (ROS) play an important role in ethanol-induced gastric ulcers $^{22}$. The gastric mucosal injury is closely related to an antioxidant action, increased lipid peroxidation and generation of free-radicals ${ }^{23}$. Organisms itself have enzymatic and nonenzymatic defenses, including CAT, SOD and GPx, which could reduced or prevent the injury of gastric tissue caused by $\mathrm{ROS}^{24}$. Therefore, we appraised kinds of oxidant-antioxidant parameters in rats gastric tissues to explore the role of oxidant stress in our experiment.

An effective indicator of oxidative stress and mucosal injuries is MDA, which is a major metabolite of lipid peroxidation. Hence, determination of MDA levels can be used to access lipid peroxidation $^{25}$. Present study showed that MDA was sharply increased by ethanol, but LMCS significantly decreased the MDA content in gastric tissue. As for endogenous antioxidants CAT, SOD and GPx, the content varieties of which indicated the ability of the organism to scavenge the $\operatorname{ROS}^{26}$. An obvious evidence observed is that ethanol inhibited the antioxidant enzymes activities of CAT, SOD and GPx in gastric tissues, which is consistent with the previous studies of alcoholic gastric ulcer symptoms ${ }^{27}$. Also, it was clear that treatment with LMCS significantly promoted the expressions of CAT, SOD and GPx at the early stage in the healing process of gastric ulcer, and reached the normal level more quickly. Researchers found that induction of antioxidant enzyme systems is important in modulation of intracellular stress, which can eliminate the ROS before they damaged the critical cellular macromolecules ${ }^{2}$. Seen in this light, LMCS prepared in this study regulated the antioxidants enzymes of CAT, SOD and GPx and their activities were increased in advanced in the process of gastric mucosal tissue repair.

There is increasing evidence that major source of ROS in gastric mucosal injury is the activated neutrophlis ${ }^{28}$, which play an vital role in the development of gastric damage by their aggregation and release of tissue-disrupting substance, such as oxygen free radicals and protease ${ }^{29}$. The neutrophil infiltration into the gastric mucosal tissues is assessed by $\mathrm{MPO}^{30}$. Our data found that LMCS significantly inhibited MPO activity and restored it to normal levels from 7 day, which was earlier than OMZ form 14 day. The reason for this discrepancy could be related to the good antiinflammatory of chitosan and sepia ink ${ }^{18}$.

Present study showed that LMCS may be used as a potential therapeutic drug for gastric ulcer in clinical, but further investigations should be studied.

\section{Conclusions}

LMCS had significantly improved therapeutic effects on ethanol-induced gastric ulceration in rats. The underlying mechanisms of its promoted therapeutic effects might involve the good ability of gastric tissue repair, reduction of oxidative damage, high radical scavenging activity and its inhibitory effects on neutrophil infiltration.

\section{References}

1. Batista LM, de Almeida AB, Lima GR, Falcão Hde S, Magri Lde P, Luiz-Ferreira A, dos Santos LC, Hiruma-Lima CA, Vilegas W, Brito AR. Gastroprotective effects (in rodents) of a flavonoid rich fraction obtained from Syngonanthus macrolepsis. J Pharm Pharmacol. 2014 Mar;66(3):445-52. PMID: 24237033.

2. Kim SJ, Kim JM, Shim SH, Chang HI. Anthocyanins accelerate the healing of naproxen-induced gastric ulcer in rats by activating antioxidant enzymes via modulation of Nrf2. J Funct Foods. 2014 Mar;7(1):569-79. doi: 10.1016/j.jff.2013.12.028.

3. Liu Y, Tian X, Gou LS, Fu XB, Li S, Lan N, Yin XX. Protective effect of 1-citrulline against ethanol-induced gastric ulcer in rats. Environ Toxicol Phar. 2012 Sep;34(2):280-7. PMID: 22634488.

4. Wallace JL, Granger DN. The cellular and molecular basis of gastric mucosal defense. Faseb J. 1996 May;10(7):731-40. PMID: 8635690

5. Liu YH, Zhang ZB, Zheng YF, Chen HM, Yu XT, Chen XY, Zhang $X$, Xie JH, Su ZQ, Feng XX, Zeng HF, Su ZR. Gastroprotective effect of andrographolide sodium bisulfite against indomethacininduced gastric ulceration in rats. Int Immunopharmacol. 2015 Jun;26(2):384-91. PMID: 25916678.

6. Lakshmi V, Singh N, Shrivastva S, Mishra SK, Dharmani P, Mishra V, Palit G. Gedunin and photogedunin of Xylocarpus granatum show significant anti-secretory effects and protect the gastric mucosa of peptic ulcer in rats. Phytomedicine. 2010 Jul;17(8-9):569-74. PMID: 19962286.

7. Younes I, Frachet V, Rinaudo M, Jellouli K, Nasri M. Cytotoxicity of chitosans with different acetylation degrees and molecular weights onbladder carcinoma cells. Int J Biol Macromol. 2016 Mar;84:2007. PMID: 26397996.

8. Kim H, Lee E, Lee IH, Lee J, Kim J, Kim S, Lee Y, Kim D, Choi $\mathrm{M}$, Kim YC, Jon S. Preparation and therapeutic evaluation of paclitaxel-conjugated low-molecular-weight chitosan nanoparticles. Macromol Res. 2014 August;22(8):805-8. doi: 10.1007/s13233014-2118-6.

9. Zheng Z, Zhang W, Sun W, Li X, Duan J, Cui J, Feng Z, Mansour $\mathrm{HM}$. Influence of the carboxymethyl chitosan anti-adhesion solution on the TGF- $\beta 1$ in a postoperative peritoneal adhesion rat. J Mater Sci Mater Med. 2013 Nov;24(11):2549-59. PMID: 23820936.

10. Chung MJ, Park JK, Park YI. Anti-inflammatory effects of lowmolecular weight chitosan oligosaccharides in IgE-antigen complex-stimulated RBL-2H3 cells and asthma model mice. Int Immunopharmacol. 2012 Feb;12(2):453-9. PMID: 22266066. 
11. Kim EH, Park SH, Chi SY, Woo HD,Yun Heo, Ito Y, Han DK, Nah JW, Son T. Enhancement effect of cell adhesion on titanium surface using phosphonated low-molecular-weight chitosan derivative. Macromol Res. 2016 Nov;24(2):1-5. doi: 10.1007/s13233-0153135-9.

12. Zhong JP, Wang G, Shang JH, Pan JQ, Li K, Huang Y, Liu HZ. Protective effects of Squid ink extract towards hemopoietic injuries induced by cyclophosphamine. Mar Drugs. 2009 Jan;7(1):9-18. PMID: 19370167.

13. Takaya Y. Biological activities of natural resources around us are now in the limelight. Yakugaku Zasshi. 2000 Nov;120(11):1075-89. PMID: 11190195.

14. Zhang W, Sun YL, Chen DH. Effects of chitin and sepia ink hybrid hemostatic sponge on the blood parameters of mice. Mar Drugs. 2014 Apr 10;12(4):2269-81. PMID: 24727395.

15. Balan T, Sani MHM, Suppaiah V, Mohtarrudin N, Suhaili Z, Ahmad Z, Zakaria ZA. Antiulcer activity of methanol extract of Muntingia calabura leaves involves the modulation of endogenous nitric oxide and non-protein sulfhydryl compounds. Pharm Biol. 2014 Feb;52(4):410-8. doi: 10.3109/13880209.2013.839713.

16. Paglia DE, Valentine WN. Studies on the quantitative and qualitative characterization of erythrocyte glutathione peroxidase. J Lab Clin Med. 1967 Jul;70(1):158-69. PMID: 6066618.

17. Balan T, Sani MH, Mumtaz Ahmad SH, Suppaiah V, Mohtarrudin N, Zakaria ZA. Antioxidant and anti-inflammatory activities contribute to the prophylactic effect of semi-purified fractions obtained from the crude methanol extract of Muntingia calabura leaves against gastric ulceration in rats. J Ethnopharmacol. 2015 Apr 22;164:1-15. PMID: 25540923.

18. Rouhollahi E, Moghadamtousi SZ, Hamdi OA, Fadaeinasab M, Hajrezaie M, Awang K, Looi CY, Abdulla MA, Mohamed Z. Evaluation of acute toxicity and gastroprotective activity of curcuma purpurascens BI. rhizome against ethanol-induced gastric mucosal injury in rats. BMC Complement Altern Med. 2014 Oct 6;14:378. PMID: 25283308.

19. Pan JS, He SZ, Xu HZ, Zhan XJ, Yang XN, Xiao HM, Shi HX, Ren JL. Oxidative stress disturbs energy metabolism of mitochondria in ethanol-induced gastric mucosa injury. World J Gastroenterol. 2008 Oct 14;14(38):5857-67. PMID: 18855985.

20. Desai KG. Chitosan Nanoparticles Prepared by Ionotropic Gelation: An Overview of Recent Advances. Crit Rev Ther Drug Carrier Syst. 2016;33(2):107-58. PMID: 27651100.

21. Mayol L, De Stefano D, Campani V, De Falco F, Ferrari E, Cencetti C, Matricardi P, Maiuri L, Carnuccio R, Gallo A, Maiuri MC, De Rosa G. Design and characterization of a chitosan physical gel promoting wound healing in mice. J Mater Sci Mater Med. 2014 Jun;25(6):1483-93. PMID: 24584669.

22. Mushtaq N, Schmatz R, Ahmed M, Pereira LB, da Costa P, Reichert KP, Dalenogare D, Pelinson LP, Vieira JM, Stefanello N, de Oliveira LS,Mulinacci N, Bellumori M, Morsch VM, Schetinger MR. Protective effect of rosmarinic acid against oxidative stress biomarkers in liver and kidney of strepotozotocin-induced diabetic rats. J Physiol Biochem. 2015 Dec;71(4):743-51. PMID: 26452500.

23. Vázquez-Velasco M, González-Torres L, López-Gasco P, Bastida S, Benedí J, González-Muñoz MJ, Sánchez-Muniz FJ. Effects of glucomannan/spirulina-surimi on liver oxidation and inflammation in Zucker rats fed atherogenic diets. J Physiol Biochem. 2015 Dec;71(4):611-22. PMID: 26239810.
24. Parmar GR. Antiulcer and antioxidant effects of Normacid syrup (a polyherbal formulation) on experimentally-induced gastric ulcers. Orient Pharm Exp Med. 2014 Jun;14(2):1-11. doi: 10.1007/s13596013-0142-2.

25. Cabrera AMZ, Geraldo ESA, José RMA. Nitric oxide and malondialdehyde in gastric contens and blood in an quine model of gastric ulcer induced by phenylbutazone. Rev Colomb Cienc Pe. 2016 Jan;21(1):43-5. doi: 10.17533/udea.rccp.v29n1a05.

26. Laloo D, Prasad SK, Krishnamurthy S, Hemalatha S. Gastroprotective activity of ethanolic root extract of Potentilla fulgens Wall. ex Hook. J Ethnopharmacol. 2013 Mar;146(2):505-14. PMID: 23384786.

27. Sidahmed HM1, Hashim NM, Amir J, Abdulla MA, Hadi AH, Abdelwahab SI, Taha MM, Hassandarvish P, Teh X, Loke MF, Vadivelu J, Rahmani M, Mohan S. Pyranocycloartobiloxanthone A, a novel gastroprotective compound from Artocarpus obtususJarret, against ethanol-induced acute gastric ulcer in vivo. Phytomedicine. 2013 Jul 15;20(10):834-43. PMID: 23570997.

28. Karakoyun B, Yüksel M, Ercan F, Erzik C, Yeğen BC. Alpha-lipoic acid improves acetic acid-induced gastric ulcer healing in rats. Inflammation. $2009 \mathrm{Feb}$;32(1):37-46. PMID: 19051000.

29. Lanchakon C, Jitbanjong T. Anti-Inflammation Property of Syzygium cumini (L.) Skeels on indomethacin-induced acute gastric ulceration. Gastroenterol Res Pract. 2015;2015:343642. PMID: 26633969.

30. Yang C, Song Y, Wang H. Suppression of RAGE and TLR9 by ketamine contributes to attenuation of lipopolysaccharide-induced acute lung injury. J Invest Surg. 2016 Oct;7:1-10. PMID: 27715346.

\section{Correspondence:}

Wei Zhang

Lingnan Normal University, Round Beibu Gulf Institute for the Protection and Utilization of Marine Animals in Medicine

Cunjin Road, 29

Zhanjiang, China

Phone: +86-759-3183445

Fax: 86-759-3183445

dhchen11@21cn.com

Received: Aug 29, 2016

Review: Oct 28, 2016

Accepted: Nov 28, 2016

Conflict of interest: none

Financial sources: Spark Program of State Ministry of Science and Technology (2014GA780071, 2013GA780091), Science and Technology Project of Zhanjiang (2016B01005).

${ }^{1}$ Research performed at Round Beibu Gulf Institute for the Protection and Utilization of Marine Animals in Medicine, Lingnan Normal University, China. 